\title{
Corrección del cistocele por vía abdominal en el curso de una histerectomía
}

\section{Doctor Héctor Enrique Bernal B.}

Profesor Agregado de Clínica Ginecológica de la Universidad Nacional, del Departamento de Ginecología y Esterilidad del Hospital de San José

En el tratamiento del prolapso genital sucede algunas veces que el cirujano se vea afrontado a practicar una histerectomía que, por las características especiales de la matriz, resulta demasiado difícil, cuando no imposible, por la vía vaginal. Tal el caso de una matriz miomatosa demasiado grande por su tamaño o demasiado irregular por su forma para franquear el hiato genital, muchas veces estrecho. $Y$ si es verdad que se ha propuesto la hemisección, e inclusive la fragmentación o despedazamiento del órgano, resultan estos procedimientos tan rebuscados y poco elegantes, cuando no tan sangrientos, que en manera alguna justifica el seguirlos. En otras ocasiones, y planteada la necesidad de una histerectomía fácil por la vía vaginal, existe alguna patología pélvica concomitante como un tumor de ovario que obliga a la exploración abdominal. Por último, aunque muy raro, por un defecto articular de la cadera que impide la aproximación del cirujano, la histerectomía vaginal, fácil en condiciones normales, se convierte en un problema muy difícil.

En cualquiera de los casos anteriores la solución lógica parece ser practicar la histerectomía por vía abdominal; pero si con ello se consigue corregir elementos tan importantes del prolapso como el hístero y el enterocele, no sucede lo mismo con el cistocele, ni con el rectocele cuando existe.

Los antiguos cirujanos, siguiendo a Kocher, creyeron resolver este problema con las pexias, y así, en la misma forma que fijaban el útero o el muñón cervical a la pared abdominal, suspendían la vagina: los resultados, sin embargo, no tardaron en desengañarlos, ya que para nada tenían en cuenta los elementos que normalmente aseguran la fijación de la vejiga y la vagina. 
Los modernos, con excelente criterio, practican las dos intervenciones por separado, sea en el mismo o en distinto acto quirúrgico: en una primera fase, por vía vaginal, corrigen el cisto y el rectocele, cuando existe, y luego por la via abdominal practican la histerectomía, pudiendo actuar de modo inverso.

Nada tenemos que objetar a esta manera de proceder en que se siguen los principios universalmente aceptados en la cura del cistocele y del colpocele anterior, es decir, la suspensión de la vejiga, previamente desprendida y elevada, por medio de la fascia vésico-vaginal reconstruída y acortada y de los ligamentos pubo-vesicales, y la resección de la parte sobrante de la mucosa vaginal. Pero si existe un procedimiento sencillo que permita hacer lo mismo por la vía abdominal, en el acto mismo en que se ejecuta la histerectomía, creemos que representa una enorme ventaja, tanto para la paciente como para el cirujano el no tener que recurrir a dos vías distintas; el tiempo será menor y el traumatismo mucho menos intenso, aparte de otras ventajas de menor cuantía.

Por primera vez tuvimos la oportunidad de ver practicar la cura del cistocele por via alta, al doctor Moore, en el "Sloan Hospital for Women". Posteriormente hemos visto las comunicaciones de Schauffer (1), y de Masters (2). Inspirados en ellos, así como en la "cistoceloplastia" de Marek (3), hemos practicado el procedimiento en algunos casos. La técnica preconizada por los autores es en esencia la misma, aunque con variaciones individuales; en tanto que Moore y Schauffer practican la resección de la mucosa y de la fascia sobrantes, Marek y Masters se limitan a fruncirlas, aunque dándole suma importancia a la aproximación mediana de los ligamentos pubo-vesicales. Por nuestra parte. hemos procedido a la manera de los primeros.

Presentamos aquí, tanto la técnica como los resultados, advirtiendo, de una vez por todas, que se trata de un procedimiento de excepción reservado únicamente para aquellos casos en que planteada la necesidad de una histerectomía abdominal, es necesario practicar también la cura del cistocele. En los demás casos permanecemos fieles a la vía vaginal, más racional, como puede deducirse de nuestra casuística: 5 casos de cistocele operados por la vía alta en cuatro años, contra 78 casos operados por la vía vaginal, lo que da apenas un porcentaje de indicaciones del 6 por 100 . 


\section{TECNICA}

Como antes lo dijimos, el procedimiento se basa exactamente en el mismo principio de corrección del cistocele por la vía vaginal, es decir, elevación de la vejiga y fijación de la misma por medio de su fascia y de los ligamentos pubo-vesicales y excisión de la mucosa vaginal sobrante. Ello presupone la disección de los elementos de suspensión antes nombrados y la amplia exposición de la pared vaginal anterior, para lo cual es necesario procurarse desde el principio un buen campo. Así, comenzada la histerectomía y previa sección y ligadura de los ligamentos redondos, se secciona el peritóneo vésico-uterino y se practica un amplio desprendimiento entre la vejiga y el segmento inferior del útero, que llega por el momento hasta la vagina; lateralmente la disección debe llegar un poco más lejos de los vasos uterinos, cerca de la pared pélvica, con lo cual se facilitará la ulterior separación entre la vejiga $\mathrm{y}$ la pared vaginal anterior y la movilización de la uretra. Los demás tiempos de la histerectomía no tienen nada de especial, por lo cual nos abstenemos de repetirlos.

Practicada la histerectomía, y reparados los bordes de sección de la vagina con pinzas de Allis largas, se continúa el desprendimiento entre la vejiga y la pared anterior de la vagina hasta alcanzar la base de la uretra, y más abajo, en caso de uretrocele. Esta disección es fácil y por lo general no provoca sangría, pero debe tenerse cuidado de no lesionar la vejiga, para lo cual es conveniente disecar únicamente con el dedo o con ayuda de una pequeña torunda y movilizar la sonda que se colocó al principio de la intervención.

Terminado el desprendimiento y levantada la vejiga se ofrece al operador el siguiente cuadro operatorio: en el centro, la vagina doblada adelante por la fascia vésico-vaginal, reforzada esta última lateralmente por los ligamentos pubo-vesicales; adelante, la cara posterior de la vejiga; hacia atrás y a los lados, los cabos ligados de los ligamentos útero-sacros y cardinales, respectivamente (figura 1). Se aplican entonces dos pinzas de Kocher rectas, sobre la pared vaginal anterior, cubierta por la fascia, en forma de limitar una V, y se secciona el pedazo de pared comprendido entre ellas, cuyo tamaño variará según las circunstancias (figura 2). Los bordes resultantes se unen con doble sutura de puntos separados con catgut cromado número 0: la pri- 
FIGURA NUMERO 1

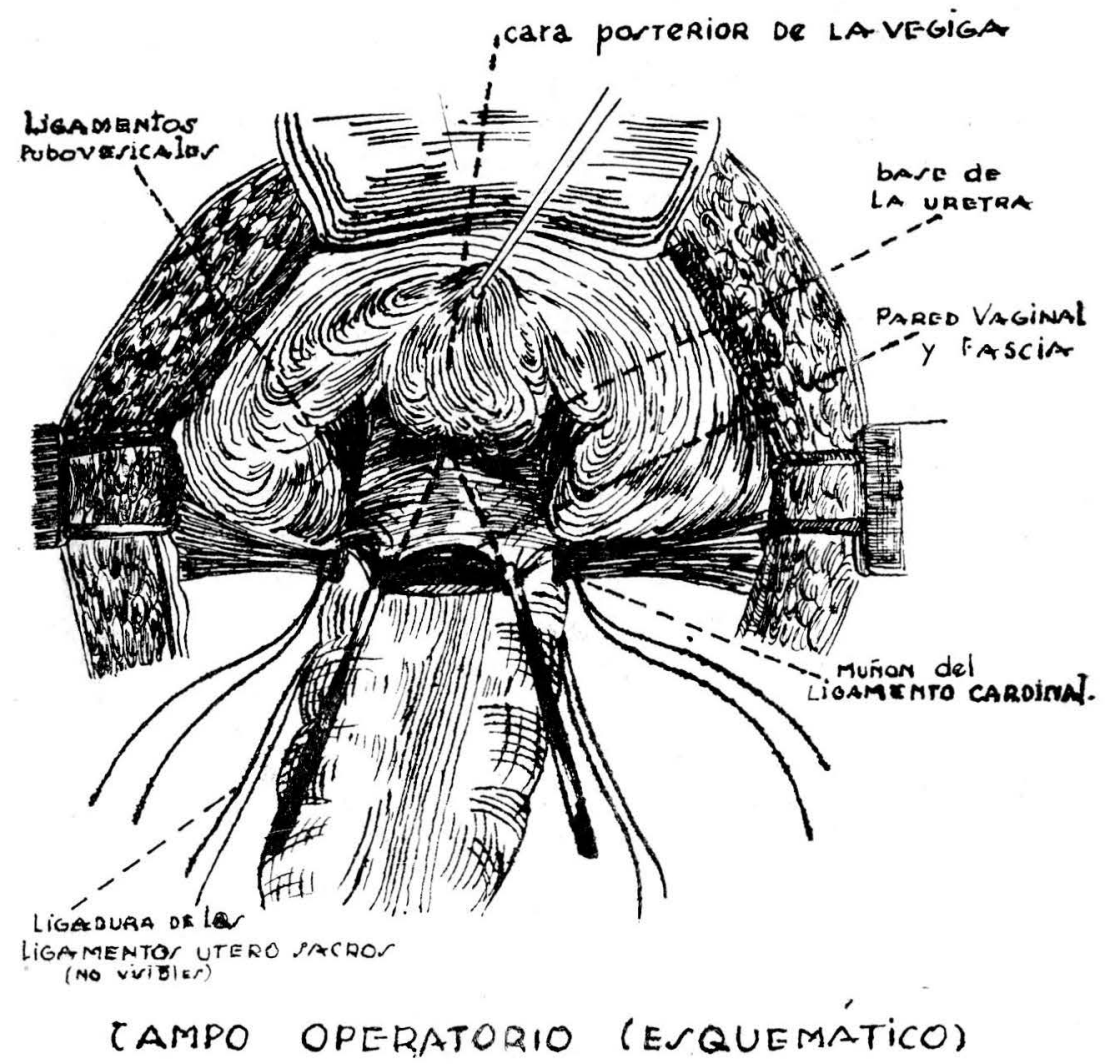

nera perforante y la segunda invaginante, aplicada únicamente sobre la fascia, y que debe llegar tan profundamente como sea posible tras del cuello de la vejiga (figura 3 ). Si los ligamentos pubo-vesicales están aparentes se pueden unir con tres puntadas de catgut cromado número 1 .

El resto de la intervención es común a cualquier histerectomía: generalmente cerramos la vagina dejando un pequeño orificio central para drenaje e incorporamos a la cúpula los ligamentos cardinales y útero-sacros. Peritonización y cierre de la pared por planos.

El post-operatorio no presenta ninguna particularidad. 
FIGURA NUMERO 2

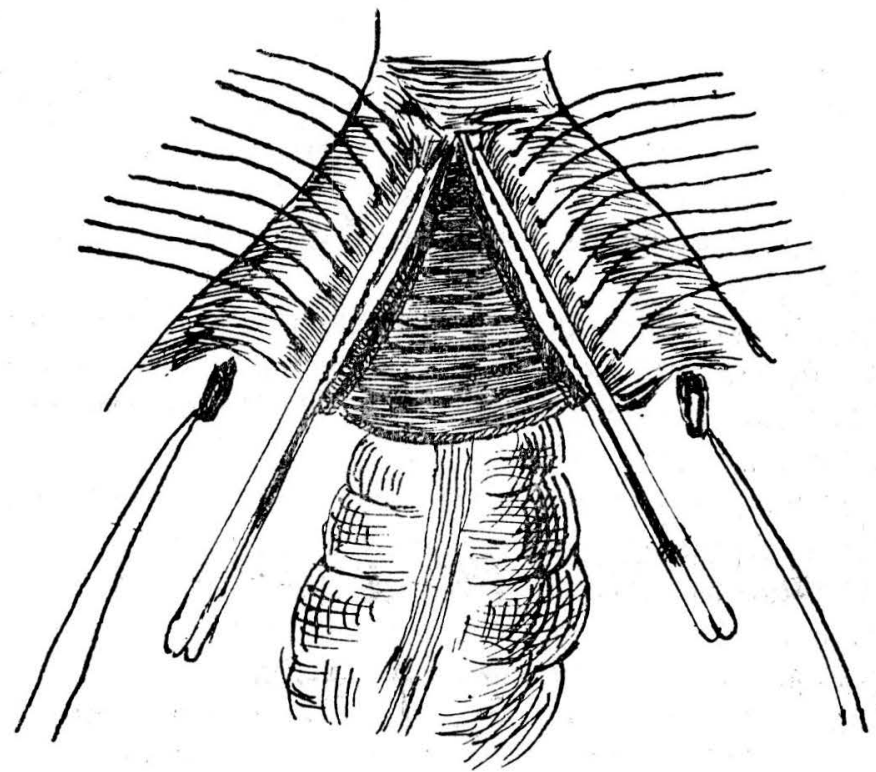

sección del colgajo en 'V Y PRIMERAS SUTURAS (PERfORANTES?

FIGURA NUMERO 3

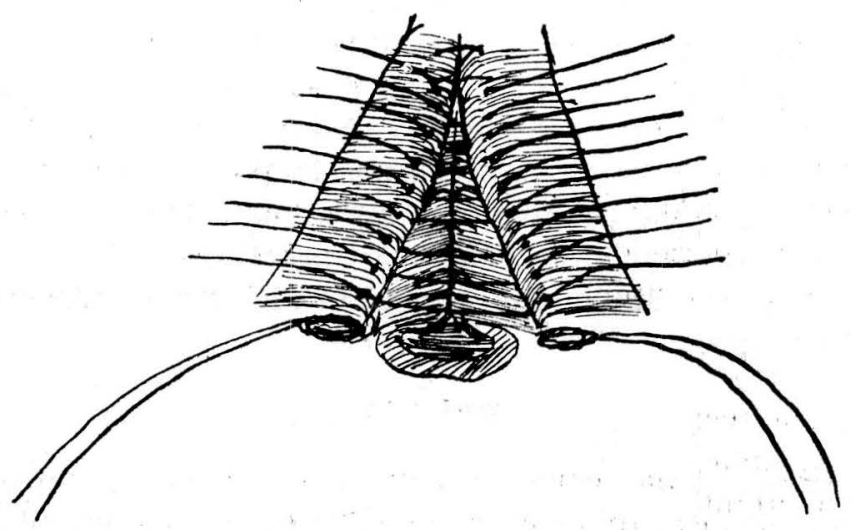

SEGUNDAS SUTURAS INVAGINANTES

(Unicamente sobre la Fascia) 


\section{CASUISTICA}

Como antes lo dijimos, comprende 5 casos de corrección de cistocele por vía alta en el curso de una histerectomía abdominal.

En 3 de ellos habia fibromioma uterino de regular tamaño que hacía difícill la operación por vía vaginal.

En otro se trataba de coexistencia de prolapso y tumor del anexo derecho.

Por último, en el quinto, a más de una matriz miomatosa, había una lesión de la cadera que impedía la correcta posición ginecológica y por consiguiente dificultaba la aproximación del cirujano al campo operatorio.

La enferma más joven tenía cuarenta años (fibromatosis uterina) y la de mayor edad sesenta y cinco años.

La técnica descrita se practicó fácilmente en 4 casos, pero ofreció dificultad en la paciente con lesión de la cadera en razón de una deformación concomitante del bacinete.

El tiempo adicional, correspondiente a la corrección del cistocele, fue aproximadamente de 10 minutos en todos los casos.

La anestesia fue raquídea en dos casos y general en los demás.

No se presentó ningún incidente en el curso de la intervención.

\section{RESULTADOS}

Excelentes en la generalidad de los casos en cuanto a la curación del cistocele. Sin embargo, hubimos de lamentar una complicación en la paciente con lesión de la cadera, quien a los pocos días de su salida del servicio observó la emisión involuntaria de orina. Al examen se comprobó la presencia de una fístula vésico-vaginal baja de diámetro aproximado de medio centímetro. Previa preparación adecuada se practicó el cierre de la fístula con feliz resultado, con lo cual quedó la paciente en perfectas condiciones.

\section{RESUMEN}

Se presenta una técnica sencilla para la corrección del cistocele por vía alta aplicable a aquellos casos en que debiendose practicar la histerectomía resulta difícil por la vía vaginal, como en el caso de fibroma; o cuando, a más del prolapso, existe alguna tumoración pélvica; o cuando, por último, debido a un de- 
fecto articular de la cadera, resulta imposible una adecuada posición ginecológica que facilite el trabajo del cirujano.

Los resultados, en cuanto a la corrección del cistocele, han sido excelentes.

Se hace énfasis en que se trata de un procedimiento de excepción aplicable únicamente a los casos anotados; en los demás se considera más lógica la vía vaginal.

\section{BIBLIOGRAFIA}

SCHAUFFER GOODRICH C.- "Management of Cystocele during Abdominal Hysterectomy". Urol. \& Cutan. Rev. 55: 269-270, May, 1951.

MASTERS WILLIAM H.-."Abdominal Approach to Cystcurethrocele Repair”. Am. J. Obst. \& Gynec. 67: 85-91, January, 1954.

MAREK CHARLES B.-Am. J. Obst. \& Gynec. 57: 345-350, February, 1949. "Abdominal Cystoceleoplasty". 